\title{
Spinocerebellar ataxia type 14
}

INSERM

\section{Source}

INSERM. (1999). Orphanet: an online rare disease and orphan drug data base.

Spinocerebellar ataxia type 14. ORPHA:98763

Spinocerebellar ataxia type 14 (SCA14) is a rare mild subtype of type I autosomal dominant cerebellar ataxia (ADCA type I; see this term). It is characterized by slowly progressive ataxia, dysarthria and nystagmus. 